\title{
Collagen-based Thiol-norbornene Photoclick Bio-ink with Excellent Bioactivity and Printability
}

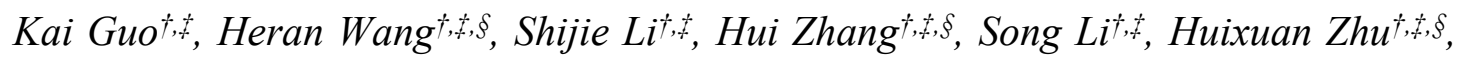

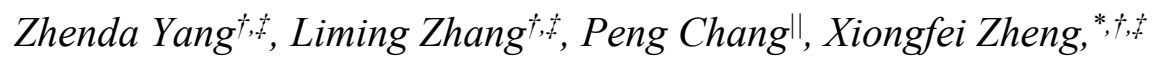

$\dagger$ State Key Laboratory of Robotics, Shenyang Institute of Automation, Chinese Academy of Sciences, Shenyang 110016, China

$\star$ Institutes for Robotics and Intelligent Manufacturing, Chinese Academy of Sciences, Shenyang 110169, China

$\S$ University of Chinese Academy of Sciences, Beijing 100049, China

$\|$ Department of plastic and reconstructive surgery, Shengjing Hospital of China Medical University, Shenyang 110004, China

E-mail: zhengxiongfei@sia.cn

Keywords: bioprinting, norbornene-functionalized collagen, neutral soluble collagen, photocrosslinkable collagen, thiol-ene collagen hydrogel 
NorCol
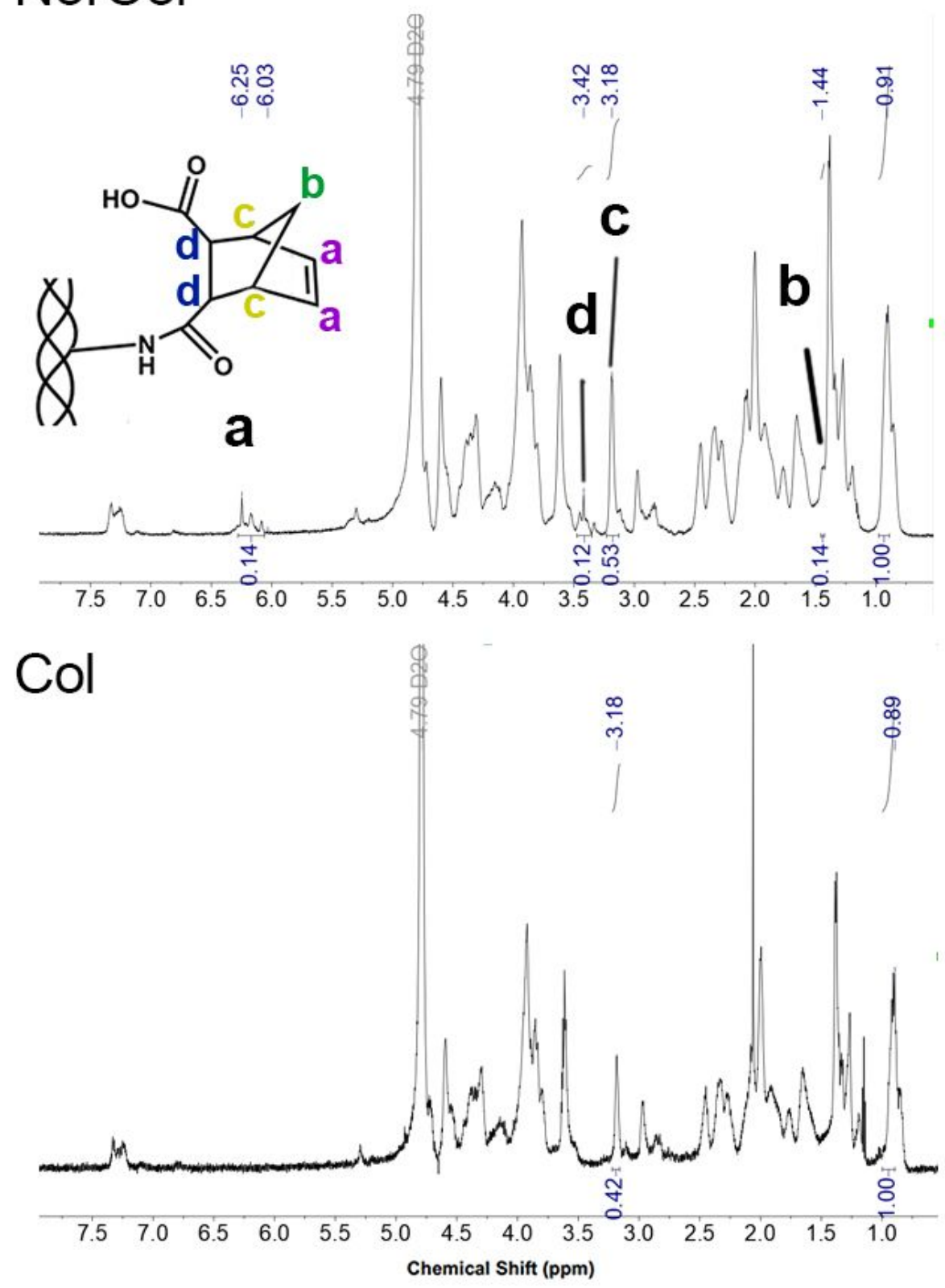

Figure S1. The resonance intensities of peaks in representative ${ }^{1} \mathrm{H}$ NMR spectrum of NorCol. The signal at $0.9 \mathrm{ppm}$ could be ascribed to the resonance in the valine (Val), leucine (Leu), and isoleucine (lle) side chain by recording ${ }^{1} \mathrm{H}$ NMR spectra of the different amino acids. The hydrophobic alkyl side chains of valine, leucine, and isoleucine can be considered to be chemically inert. The intensity of $\mathrm{C}$ of NorCol at 3.2 can be obtained by subtracting that of collagen. Half of intensity of the methyl resonance at $0.9 \mathrm{ppm}$ was defined as 1 . 


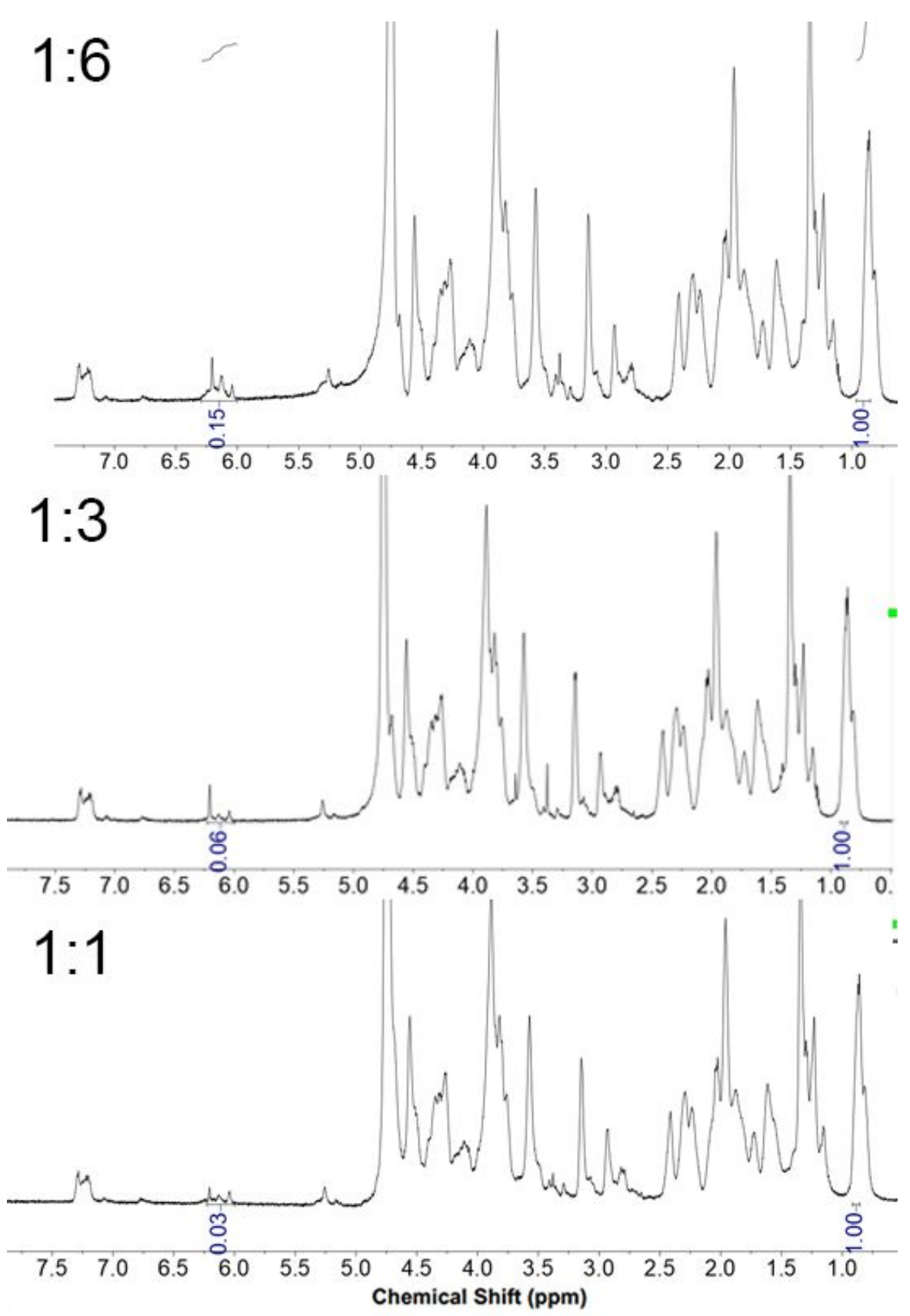

Figure S2. Representative ${ }^{1} \mathrm{H}$ NMR spectrum of NorCol with three norbornene degrees. Half of intensity of the methyl resonance at $0.9 \mathrm{ppm}$ was defined as 1 . 


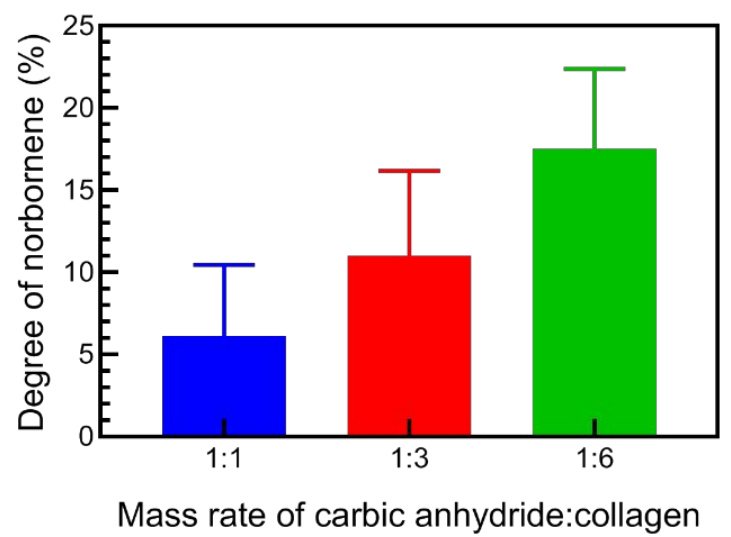

Figure S3. Degree of norbornene as measured by the Habeeb method. The degree of norbornene was determined for various mass ratios of carbic anhydride and collagen (1:1, 3:1 and 6:1) in the synthesis reaction.

(a)
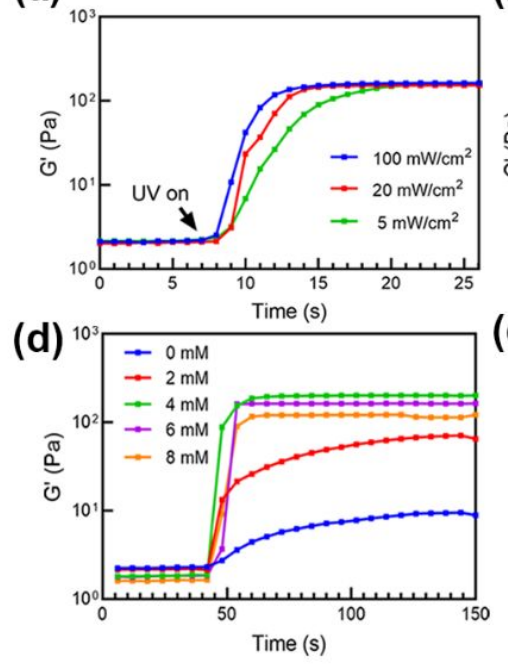

(b)

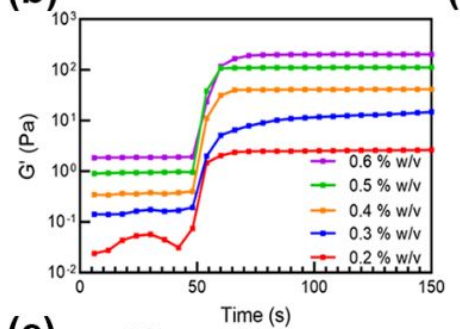

(e)

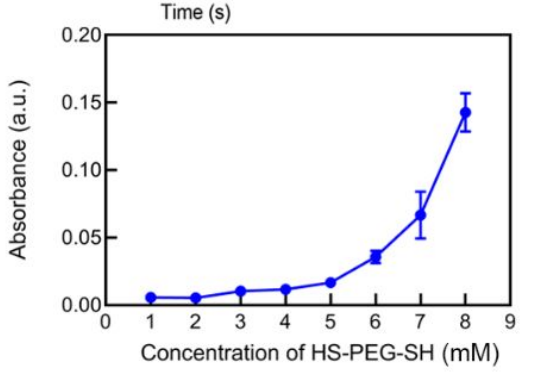

(c)

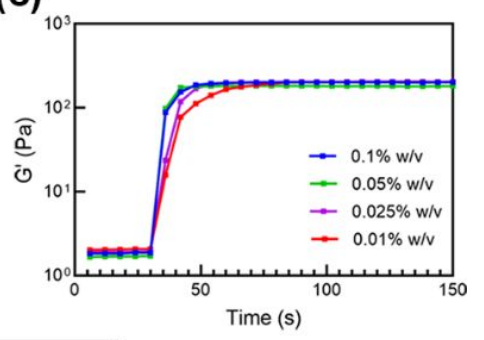

. 
$4 \mathrm{mM}, 6 \mathrm{mM}$ and $8 \mathrm{mM}$ ). (e) Relative free thiol residual concentration after the reaction of NorCol and HSPEG-SH at different concentrations.

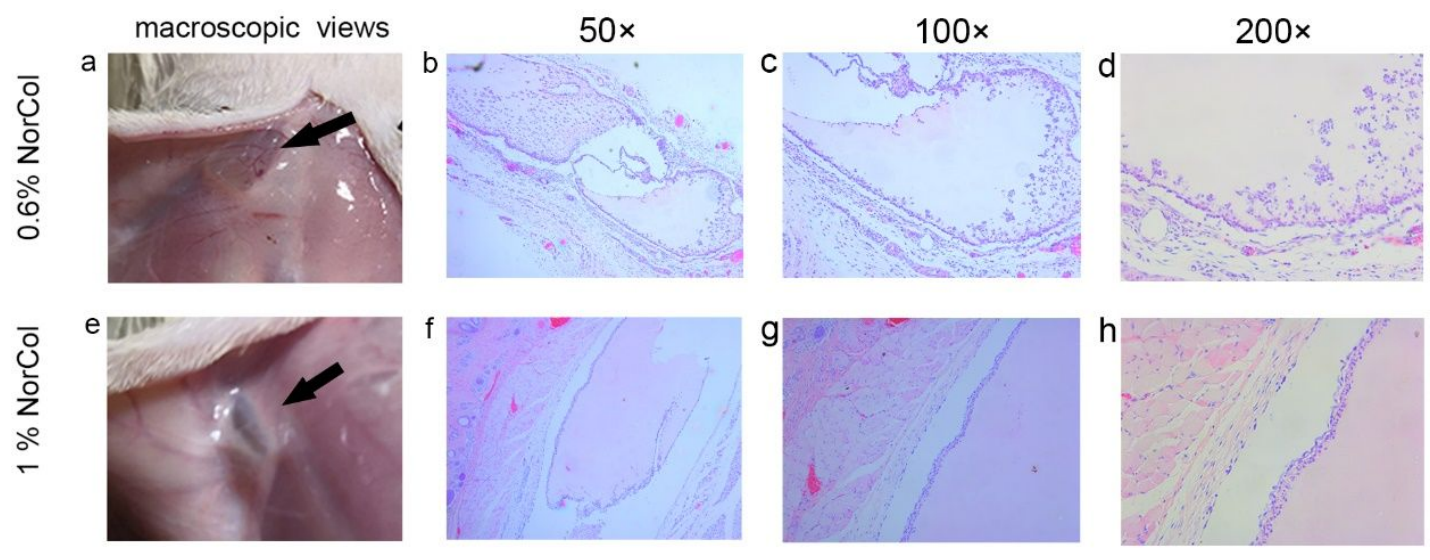

Figure S5. Evaluation of NorCol hydrogels in vivo on day 7. (a) Macroscopic views of transplanted NorCol hydrogels $(0.6 \% \mathrm{w} / \mathrm{v})$ after $7 \mathrm{~d}$. (b-d) HE-stained sections of the interface between tissue and NorCol hydrogels $(0.6 \% \mathrm{w} / \mathrm{v})$ at different magnifications on day $7 .(\mathrm{e})$ Macroscopic views of transplanted NorCol hydrogels ( $1 \% \mathrm{w} / \mathrm{v})$ after $7 \mathrm{~d}$. (f-h) HE-stained sections of the interface between tissue and NorCol hydrogels $(1 \% \mathrm{w} / \mathrm{v})$ at different magnifications on day 7.
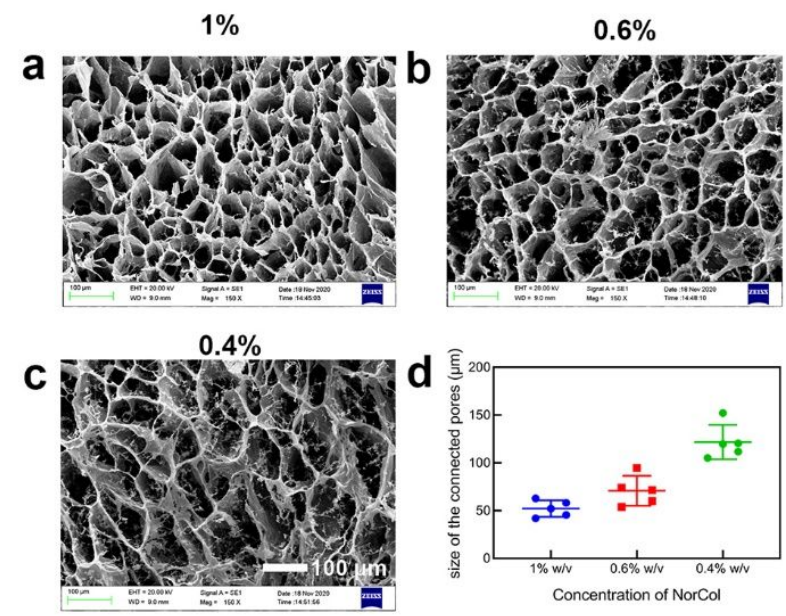

Figure S6. SEM images of NorCol hydrogels with different concentrations (a-c) and average pore size (d). 


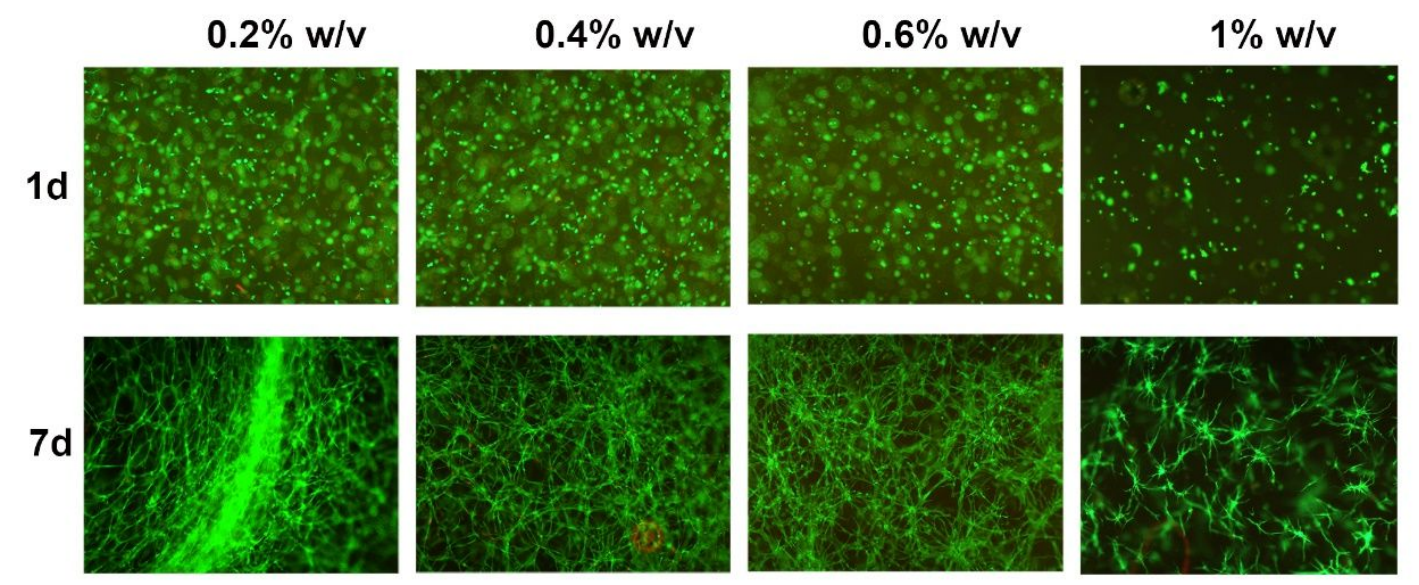

Figure S7 Fluorescence images of live/dead staining of FB cells in NorCol hydrogels formed by different concentrations of NorCol on day 1 (24 h post-gelation) and on day 7.

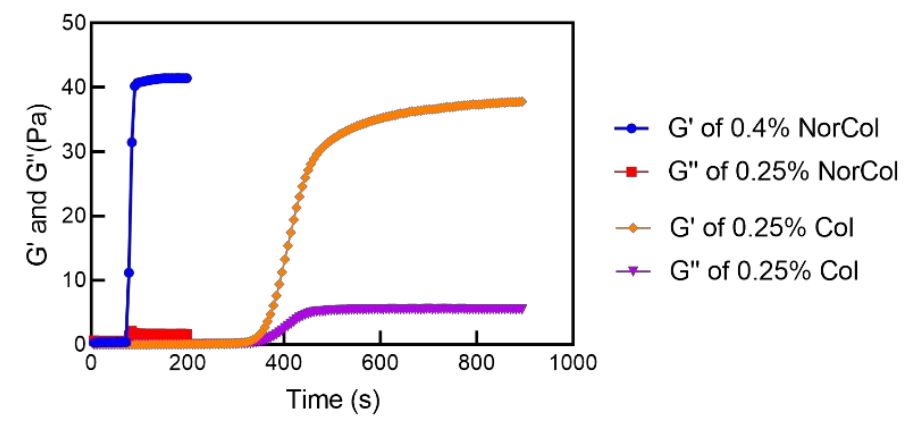

Figure S8 In situ photorheometry of NorCol hydrogels $(0.4 \% \mathrm{w} / \mathrm{v})$ and Rat tail collagen $(0.25 \% \mathrm{w} / \mathrm{v})$.
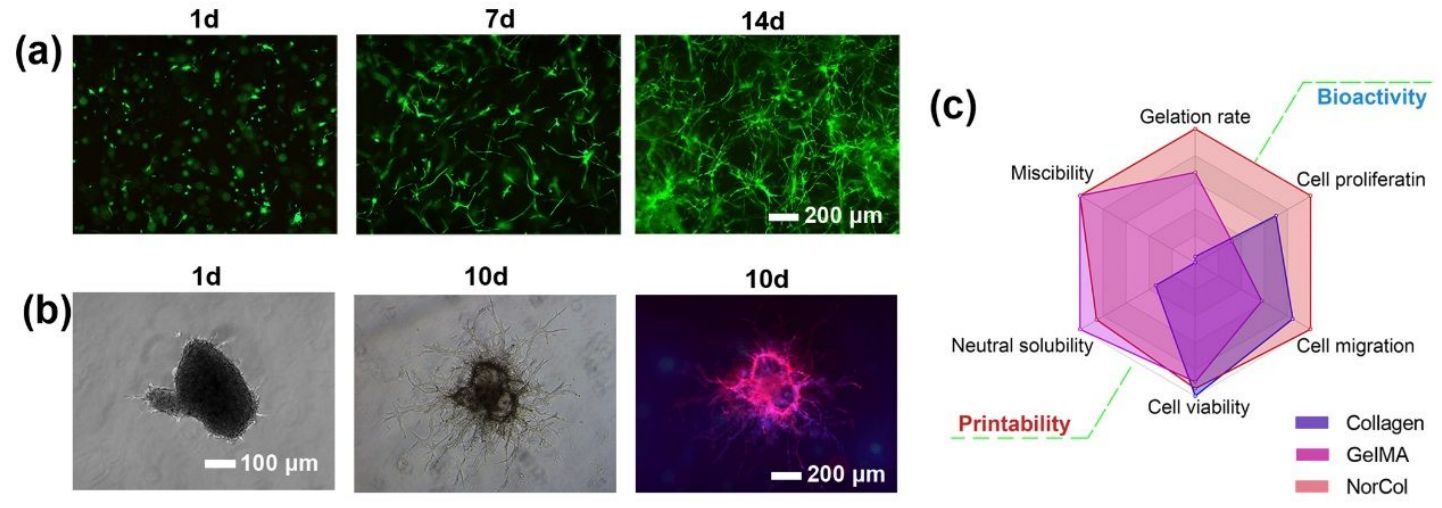

Figure S9. (a) Fluorescence micrographs showed viability, visible proliferation and spreading of encapsulated HDFBs on day 1 , day 7 , and day 14 in GelMA hydrogels (5\% w/v). (b) Migration of FB 
spheres on day 1 and day 10 in GelMA hydrogels $(0.4 \%$ w/v), cells were stained for nuclei (blue) and Factin (red). (c) Spider diagram showing printability and bioactivity of different hydrogels.

Table S1. Quantification of printability and bioactivity performance of collagen, GeIMA and NorCol hydrogels.

\begin{tabular}{|c|c|c|c|c|c|c|}
\hline $\begin{array}{l}\text { Study } \\
\text { groups }\end{array}$ & $\begin{array}{l}\text { Cell } \\
\text { proliferation } \\
\text { (a.u.) }\end{array}$ & $\begin{array}{l}\text { Cell } \\
\text { migration } \\
\text { (um) }\end{array}$ & $\begin{array}{l}\text { Cell } \\
\text { viability } \\
(\%)\end{array}$ & $\begin{array}{l}\text { Gelation } \\
\text { rate } \\
(1 / s)\end{array}$ & $\begin{array}{l}\text { Neutral } \\
\text { solubility } \\
\text { (a.u.) }\end{array}$ & $\begin{array}{l}\text { Miscibility } \\
\text { (with gelatin } \\
\text { and } \\
\text { alginate) }\end{array}$ \\
\hline Collagen & $2.18 \pm 0.36$ & $\begin{array}{l}872.33 \pm \\
129.77\end{array}$ & $\begin{array}{l}98.53 \pm \\
0.77\end{array}$ & $\begin{array}{l}0.0019 \pm \\
0.000086\end{array}$ & $\begin{array}{l}0.525 \pm \\
0.014\end{array}$ & $0 / 2$ \\
\hline GelMA & $0.99 \pm 0.16$ & $\begin{array}{ll}595 & \pm \\
20.07 & \end{array}$ & $\begin{array}{l}88.01 \pm \\
5.31\end{array}$ & $\begin{array}{l}0.029 \pm \\
0.0032\end{array}$ & $\begin{array}{ll}1.53 & \pm \\
0.032 & \end{array}$ & $2 / 2$ \\
\hline NorCol & $3.11 \pm 0.1$ & $\begin{array}{ll}1032 & \pm \\
49.42 & \end{array}$ & $\begin{array}{l}92.98 \pm \\
3.27\end{array}$ & $\begin{array}{l}0.043 \pm \\
0.011\end{array}$ & $\begin{array}{ll}1.31 \quad \pm \\
0.061\end{array}$ & $2 / 2$ \\
\hline
\end{tabular}
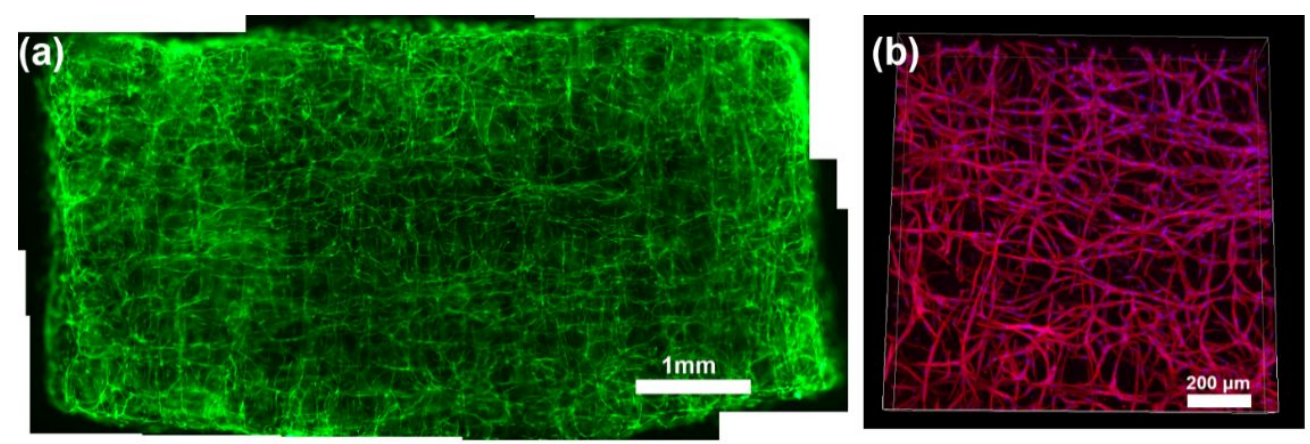

Figure S10. (a) Live/dead stain and (b) confocal image of HDFBs (stained for nuclei and F-actin of HDFBs) within printed NorCol hydrogels on day 5 using temperature-sensitive extrusion bioprinting, with cells spreading uniformly along the printing direction. 


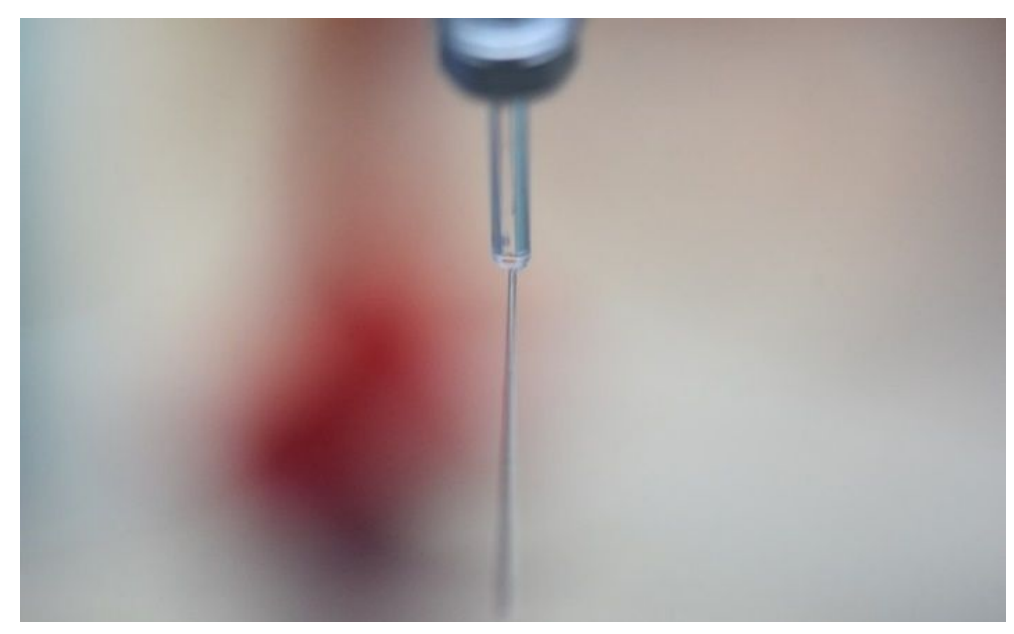

Figure S11. NorCol filaments $(0.55 \mathrm{~mm})$ squeezed out of a quartz tube.

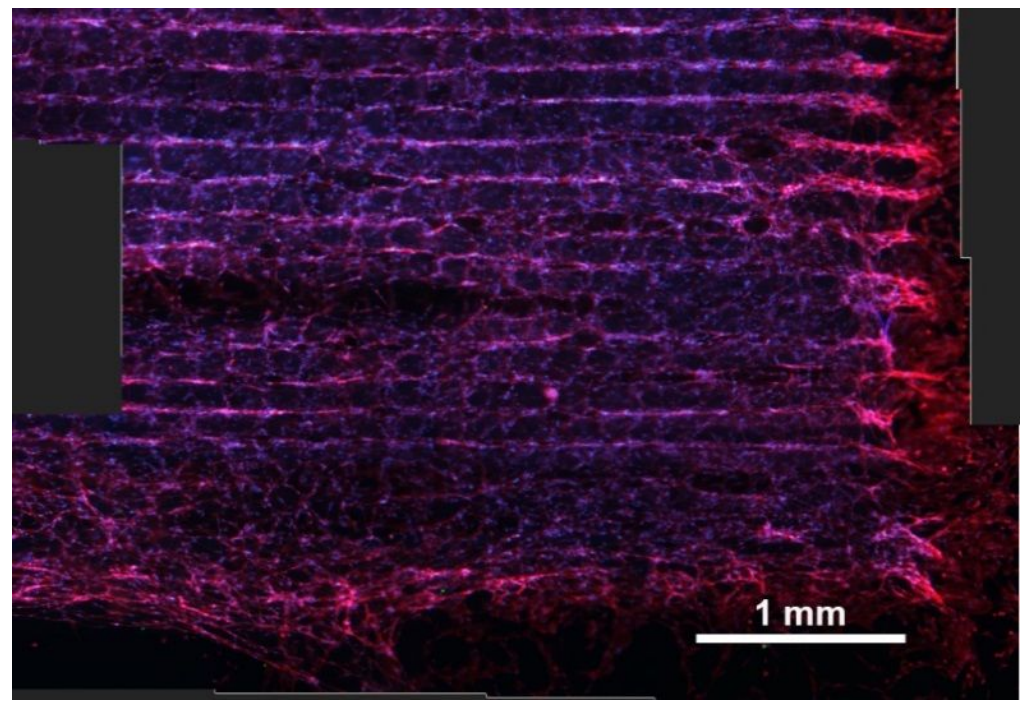

Figure S12. HDFBs within the NorCol hydrogels on day 5 using SLA bioprinting, with cells spreading uniformly along the printing direction. 